\title{
Partial splenic embolization in a child with hereditary spherocytosis
}

\author{
M. Jiménez * \\ C. Azcona * \\ L. Castro * \\ J. I. Bilbao \# \\ P. León * \\ L. Sierrasesúmaga \\ * Department of Paediatrics \\ \# Department of Radiology \\ Clínica Universidad de Navarra. \\ Avda. Pio XII s/n. E-31080. \\ Pamplona. Navarra. Spain
}

Partial splenic embolization (PSE) was introduced as an alternative to splenectomy to avoid the risk of post-splenectomy sepsis and to reduce the number of situations in which surgery would be dangerous or not feasible [5]. PSE is an accepted therapy for the treatment of secondary hypersplenism in various disorders, including oesophageal variceal haemorrhage [3], thalassaemia major [5], portal hypertension [1], painful splenomegaly [2], Gaucher disease [9], hypersplenism in cirrhosis [5], and prior to myelosuppressive treatment in hepatocarcinoma and active chronic hepatitis $[2,3]$.

As an alternative to surgical splenectomy, PSE was performed on a 7-year-old girl with hereditary spherocytosis and hypersplenism who initially presented with a haemolytic crisis; haemoglobin values of $6.8 \mathrm{~g} / \mathrm{dl}$, jaundice and splenomegaly. She needed blood transfusions on two occasions due to persistent anaemia, with $\mathrm{Hb}$ values between 6.8-9 $\mathrm{g} / \mathrm{dl}$. PSE was performed following the Spigos protocol [8].

Peripheral blood cell counts were repeated on days 1, 3, 7 and 15, and then 1, 3, 6, and 12 months after PSE (see Table 1). Abdominal ultrasound 1 month after PSE showed a $17 \%$ reduction in spleen size, with embolization of approximately $75 \%$ of the spleen.

Maddison [7] performed the first successful splenic arterial embolization in 1973. The procedure was initially associated with significant morbidity and mortality, but subsequent series report substantially improved results [6]. We performed the embolization technique described by Spigos $[1,3,6,8]$ because it has a very low risk of complications, although Israel et al. [5] recently reported a lower rate of complications using polyvinyl alcohol.

The increase in haemoglobin values found in our patient has been observed in patients affected by other diseases who have required PSE [5]. The thrombocytosis observed in our patient during the first 15 days after PSE that returned to normal values over 3 months, has been previously reported $[3,5]$. This increase in platelet count appears to be 
due to the increase in sequestration in the spleen. There were no modifications in the white cells. The clinical course in our patient was similar to that described by others [3, 6], with moderate fever for 3 days, mild abdominal pain and vomiting (known as the postembolization syndrome) and alleviated by symptomatic treatment [2]. We did not observe any other complications (e.g. pleural effusion, pancreatitis, pneumonia [1]).

We attempted to infarct between $70 \%$ and $80 \%$ of the splenic parenchyma, as it has been clinically and experimentally demonstrated that a $30 \%$ remnant of splenic tissue can provide protection against infection [4].

We suggest PSE to be an acceptable alternative to splenectomy in a child with hereditary spherocytosis and secondary hypersplenism, owing to the simplicity of the technique, the favourable outcome and the absence of complications in our case.

\section{REFERENCES}

1. Alwmark A, Benmark S, Gullstarand P, Joelsson B, Lunderquist A, Owman T (1982) Evaluation of splenic emobilization in patients with portal hypertension and hypersplenism. Ann Surg 196: 518-524.

2. Bilbao JL, Sangro B, Longo J, Zozaya JM, Fernández-Virgós A, Aquerreta JD, Beloqui O, Prieto J (1992) Splenic embolization prior myelosuppressive treatment in hepatocarcinoma and active chronic hepatitis. Eur J Radiol $15: 211-214$

3. Brandt CT, Rothbarth LJ, Kumpe D, Karrer FM, Lilly JR (1989) Splenic embolization in children: long-term efficacy. J Pediatr Surg 24: 642-645

4. Dickerman JD (1979) Splenectomy and sepsis: a warning. J Pediatr 63:938-941

5. Israel DM, Hassal E, Culham JA, Phillips RR (1994) Partial splenic embolization in children with hypersplenism. J Pediatr 124:95-100

6. Kumpe DA, Rumack CM, Pretorius DH, Stoecker TJ, Stellin GP (1985) Partial splenic embolization in children with hypersplenism. Radiology $155: 357-362$

7. Maddison FE (1973) Embolic therapy of hypersplenism. Invest Radiol 8: 280-281

8. Spigos DG, Jonasson O, Mozew M, Capek V (1979) Parcial splenic embolization in the treatment of hypersplenism. Am J Roentgenol 132: 777-782

9. Thanopoulos BD, Frimas CA (1982) Partial splenic embolization in the management of hypersplenism secondary to Gaucher's disease. J Pediatr 101: 740743 


\begin{tabular}{|l|c|c|c|c|c|c|c|c|c|}
\hline \multicolumn{7}{|c|}{ Table 1. Haemoglobin, platelets, leucocytes and total bilirubin } \\
& $\begin{array}{c}\text { Before } \\
\text { PSE }\end{array}$ & $\mathbf{1}$ day & $\mathbf{3}$ day & $\mathbf{7}$ day & $\mathbf{1 5}$ day & $\mathbf{1}$ mo & $\mathbf{3}$ mo & $\mathbf{6}$ mo & $\mathbf{1 2}$ mo \\
\hline & $6.8-8$ & 9.1 & 9.5 & 10.1 & 10.5 & 12.6 & 12.8 & 12.5 & 12.2 \\
\hline Haemoglobin (g/dl) & 334 & 374 & 420 & 635 & 902 & 571 & 471 & 450 & 436 \\
\hline Platelets $\left(10^{9} / 1\right)$ & 7.4 & 8.0 & 7.3 & 7.4 & 8.1 & 7.9 & 7.1 & 7.2 & 8.6 \\
\hline Leucocytes $\left(10^{9} / 1\right)$ & 3.4 & & & 0.5 & & & 0.6 & & 0.1 \\
\hline Total bilirubin (mg/dl) &
\end{tabular}

